EL TERRORISMO EN EL CÓDIGO PENAL COLOMBIANO TERRORISM IN THE COLOMBIAN CRIMINAL CODE O TERRORISMO NO CÓDIGO PENAL COLOMBIANO

Henry Torres Vásquez 


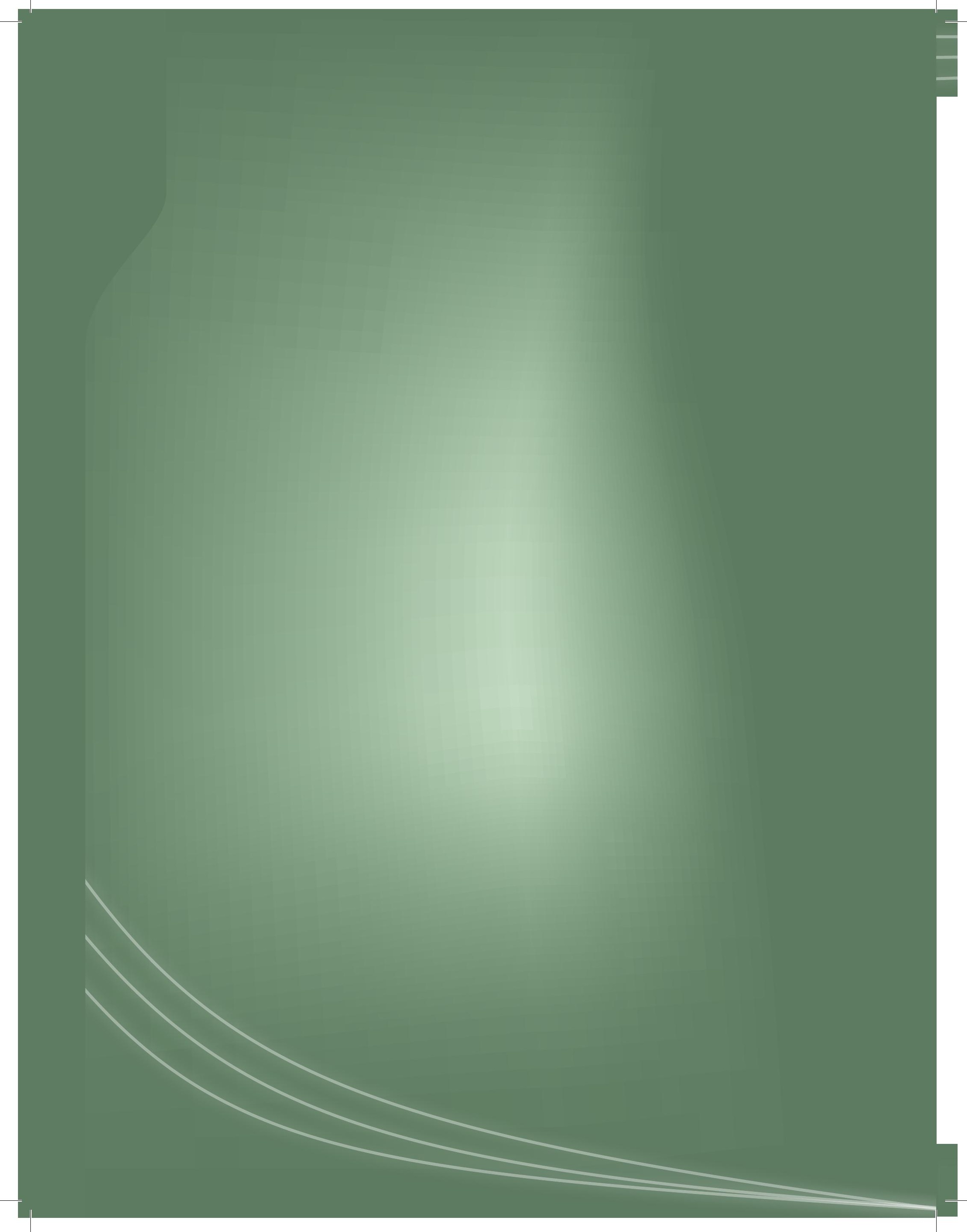




\section{EL TERRORISMO EN EL CÓDIGO PENAL COLOMBIANO*}

\section{TERRORISM IN THE COLOMBIAN CRIMINAL CODE}

\section{O TERRORISMO NO CÓDIGO PENAL COLOMBIANO}

\section{Henry Torres Vásquez**}

\section{RESUMEN}

En el presente artículo se intenta de manera general abordar el terrorismo desde el punto de vista puramente legal, doctrinal y jurisprudencial. En Colombia es necesario y en ello radica este aporte, generar discusión jurídica respecto a la implementación de los delitos de terrorismo. Aquí se pretende puntualizar los tipos penales nuestros y se estudian algunos aspectos imbricados en los mismos, sin que ello sea un aspecto formal y dogmático, sino que al contrario, es un análisis a la luz de las actuales interpretaciones sobre el terrorismo, lo cual no obsta para hacer algunos muy breves comentarios al respecto. Los elementos constitutivos de los bienes jurídicos Seguridad Pública y Derecho internacional Humanitario son analizados junto a los ingredientes normativos de los dos tipos penales estipulados en nuestro código penal.

\section{PALABRAS CLAVE}

Terrorismo, Seguridad Pública, Derecho internacional Humanitario, Código Penal.

Fecha de Recepción del Artículo: 16 de Octubre de 2009

Fecha de Aceptación del Artículo: 12 de Diciembre de 2009.

* Artículo de revisión sobre la investigación: Terrorismo y seguridad, sus consecuencias sobre los Derechos Humanos, perteneciente a la línea de investigación: Derechos Humanos y Derecho Internacional Humanitario, en el grupo Derechos Humanos, Derecho Penal y garantías procesales, de la Facultad de Derecho de la Universidad Libre, sede Bogotá. Grupo categoría C, código COL0035779.

** Abogado de la Universidad Nacional de Colombia. Doctor en Empresa y Sistema Penal, Universitat Jaume I de Castellón, España. Docente investigador de jornada completa, Facultad de Derecho, Universidad Libre, Sede Bogotá D. C.

\section{ABSTRACT}

This article attempts to address terrorism in general, from views that are purely legal, doctrinal and jurisprudential. In Colombia this approach is necessary and herein lies this contribution, which consists to create a legal debate regarding the implementation of terrorist crimes in the Colombian legal system. It should be noted, therefore, the existing criminal types and its legal aspects, without this being elaborated under a formal or dogmatic aspect, but instead developed as a study in light of current interpretations of terrorism, which is not cause detriment of those brief comments made about the subject. The elements of legal rights relating to the Public Security and International Humanitarian Law are analyzed along with the legal foundations of the two types of crimes under the Colombian Penal Code.

\section{KEY WORDS}

Terrorism, Public Security, International Humanitarian Law, Criminal Code.

\section{RESUMO}

Este artigo tenta abordar o terrorismo em geral, desde visões que sejam puramente legal, doutrinária e jurisprudencial. Na Colômbia tal se faz necessário e esta contribuição tem como contribuição gerar um debate jurídico sobre a implementação dos crimes de terrorismo no sistema legal colombiano. Salienta-se, portanto, tipos penais existentes e alguns aspectos deles constantes, sem que isso seja elaborado sob um aspecto formal ou dogmático, mas, ao invés, desenvolve-se como um estudo realizado à luz das interpretações atuais do terrorismo, o que não prejudica que breves comentários sejam feitos à respeito do assunto. Os elementos constitutivos dos bens jurídicos relativos à Segurança Pública 
e ao Direito Humanitário Internacional são analisados junto com os fundamentos legais dos dois tipos de crimes previstos no código penal colombiano.

\section{PALAVRAS-CHAVE}

Terrorismo, Segurança Pública, Direito Internacional Humanitário, Código Penal.

\section{INTRODUCCIÓN}

Uno de los inconvenientes más serios de la sociedad contemporánea es el que tiene que ver con el terrorismo, específicamente por la inseguridad colectiva que genera su accionar. Pero a pesar de lo complejo del problema, ni la doctrina ni la jurisprudencia se ha puesto de acuerdo sobre qué entender por terrorismo, por terror o por terrorista. La indefinición de estos términos, en verdad, lo que hace es facilitar el encuadramiento en el tipo penal de terrorismo de conductas que no son terrorismo, sin embargo, es obviamente necesario tener un tipo penal que recoja ese tipo de acciones criminales, por lo cual del caso colombiano nos ocuparemos en lo que sigue. Es de advertir que en este estudio se afronta la complicada realidad del terrorismo en el mundo actual, pero no se entra a confrontar nuestros tipos penales con las severas críticas que en torno al tema surgen en todo el planeta, especialmente, en cuanto a la laxitud de los mismos, de la misma manera no se hace un examen desde el derecho comparado ni a favor ni en contra; tampoco hay respuestas definitivas al terrorismo y su indefinición de manera cierta, que ha propósito es uno de los debates menos pacíficos en la doctrina especializada.

\section{PROBLEMA DE INVESTIGACIÓN}

En este artículo se acomete resolver, al menos en parte, el estudio de los bienes jurídicos que en Colombia existen en el código penal y que hacen referencia al terrorismo. Se ha buscado explicar el fenómeno del terrorismo, luego de hacer diferentes preguntas, entre ellas las principales han sido, ¿Qué se entiende por terrorismo en nuestro país, desde el punto de vista legal?, por supuesto que existen otras preguntas anejas a la anterior, como ¿Cuáles son los bienes jurídicos que se desean proteger con los tipos penales que taxativamente están consagrados en nuestro código penal?, y ¿Qué dice alguna parte de la doctrina sobre esos bienes jurídicos? Necesariamente, se ha indagado de forma muy genérica sí: ¿Un Estado debe permitir el uso de cualquier medio o método ilegal, para contrarrestar el terrorismo, sin que pueda caer en el nihilismo ${ }^{1}$ ? De las respuestas a estos interrogantes, en los que obviamente quedan muchas inquietudes en torno al manido asunto del terrorismo, nos ocuparemos en seguida.

\section{METODOLOGÍA}

Se ha efectuado una metodología de investigación muy normativa, con apoyo jurisprudencial, el estudio se centra en el código penal colombiano y se ha acudido al derecho y a la doctrina internacional para hacer un compendio comparativo doctrinal, que permite un acercamiento al derecho penal internacional y a la complejidad del terrorismo. De hecho el apoyo axial radica en los autores españoles, alemanes y norteamericanos sobre la materia. Todo ello ha permitido un análisis descriptivo analítico desde el prisma de lo sociojurídico, con un enfoque critico social.

\section{RESULTADOS}

\section{Los bienes jurídicos protegidos}

En Colombia, el terrorismo está consagrado en

1 Nihilismo significa dejarse de contemplaciones, «una guerra contra el terror que no luche por mantenerse a raya contra la tentación de hacerse tan indiscriminada como los actos terroristas perderá, con toda seguridad, tanto su legitimidad política como su legitimidad moral». IGNATIEFF, M. (2005). El mal menor, ética política en una era de terror. Barcelona: edit. Taurus, p. 171 y 173. 
dos artículos de la codificación penal de forma directa. En primer lugar existe el artículo 144 del Código Penal, en el que se hace alusión al acto de terrorismo; que hace parte de los tipos penales que reciben el nombre de delitos contra personas y bienes contra el Derecho Internacional Humanitario en adelante DIH y, que junto a otros 29 tipos penales sancionan las infracciones graves, al derecho internacional de los conflictos armados. Aquí se castigan las acciones humanas condenadas por el DIH que de manera ejemplar están tipificadas en el Código Penal.

Por mandato Constitucional del artículo 214 en el cual se dice «En todo caso se respetarán las reglas del derecho internacional humanitario». La jurisprudencia de la Corte Constitucional ha sido enfática al señalar que el respeto por el derecho humanitario es inmediato, permanente $\mathrm{y}$ prevalece en el orden interno, en situaciones de normalidad, e incluso en los estados de excepción, así se dijo en Sentencia 574 de 1994 «Las reglas del Derecho Internacional Humanitario son hoy - por voluntad expresa del Constituyente - normas obligatorias per se sin ratificación alguna previa o sin expedición de norma reglamentaria. Y lo son "en todo caso" como lo señala significativamente la propia Carta» (Corte Constitucional, 1994). Derivada de esa cobertura Constitucional y legal se hace efectiva su aplicación, en vista de asegurar la protección de aquellos comportamientos que se realizan "con ocasión y en desarrollo del conflicto armado" sobre las personas y los bienes protegidos por el DIH.

Ahora bien, este es un ámbito material ineludible a la hora de tipificarse el delito. Es preciso resaltar que este es un marco, que sirve como concepto para poder entender que las conductas realizadas por fuera del conflicto armado o con su ocasión, serán tipificadas por adecuarse a otros tipos penales. Respecto a los distintos bienes jurídicos que el legislador quiere tutelar, que en este caso se refieren a un solo bien jurídico que de manera genérica es protegido, esto es el DIH.

Es un elenco axiológico en el que se concentraron una serie de valores humanitarios que desde los Convenios de Ginebra la comunidad internacional ha tenido como prioritarios. Dentro de él se hallan otros muchos bienes jurídicos tales como: la vida, integridad y dignidad personal; la libertad e integridad sexual; la libertad y autonomía personal y el debido proceso; métodos y medios y de combate ilícitos; delitos contra la asistencia humanitaria; contra los bienes protegidos, contra la protección de la población civil y despojo en el campo de batalla.

Como se vislumbra este es un conjunto normativo de carácter muy amplio con un carácter supraestatal, que tiene por fin "humanizar" los conflictos armados estableciendo normas para la conducción de las hostilidades y para la protección de las víctimas de la guerra. Dicho lo anterior hay lugar a hacer los siguientes comentarios respecto al bien jurídico tutelado que ciertamente contiene dos clases, por un lado unos bienes jurídicos de tipo personal, como la vida por ejemplo, y por otro, en el que se integran bienes jurídicos que lesionan o pongan en peligro bienes de índole material.

En segundo lugar, en el artículo 343 se tipifica el delito de terrorismo y sus conexos más habituales como son: el concierto para delinquir ${ }^{2}$ y la instigación a cometer delitos de terrorismo etc. En el estudio del tipo penal del artículo 343, se debe partir de estudiar el bien jurídico que nuestro legislador quiso proteger. No hay voces en Colombia disientan que el bien

2 Es muy polémico el artículo 340 del Código Penal, concierto para delinquir ya que explicita un tipo penal que entraña la anticipación de la punibilidad ya que castiga la concertación; luego se castiga a un individuo por la sola pertenencia, incluso sin haber cometido ningún delito. Una extensa crítica a ese tipo penal, en: APONTE CARDONA (2006). Guerra y derecho penal del enemigo. Bogotá D. C.: Grupo Editorial Ibáñez, p. 313. 
jurídico protegido es: la Seguridad Pública, la cual es aceptada sin excepciones. Márquez entiende por seguridad pública el derecho de todos los colombianos «a no ser víctimas de actos potencialmente capaces de ocasionar intranquilidad colectiva» (Márquez C. A. y Paz G., 2008).

De forma muy directa con el bien jurídico Seguridad pública se intenta proteger a la sociedad de ataques contra obras e instalaciones que contienen fuerzas peligrosas, atentados a la subsistencia y devastación. De forma indirecta con la Seguridad pública se pretende evitar la utilización de medios y métodos de guerra ilícitos, actos de terrorismo, destrucción $\mathrm{y}$ apropiación de bienes. Aunque parezca paradójico, la seguridad pública se dice que es mayor y mejor, cuando menor sea el grado de libertad ${ }^{3}$, y consiguientemente, es cuando entra en crisis la seguridad jurídica en términos de respeto a las garantías de los derechos de libertad, ya que se considera que la libertad es contraria a la seguridad del Estado. Las críticas a la defensa a ultranza de esa clase de seguridad, se radicalizan cuando el Estado utiliza métodos ilegales, de tal modo que nunca hay justificación moral a la violencia estatal, los actos de terror cuando son en nombre de la seguridad pública, llega a ser avalada por amplios sectores, tal como indica López Rey y Arrojo (1983).

Normalmente, «La violencia institucional se halla las más de las veces justificada, y tal justificación comprende de la criminalidad perpetrada por ella». Lo cual es a todas luces ni tolerable ni puede ser permisible.

Actualmente, el derecho penal de modo preferente procura el sostenimiento de una seguridad general. En virtud del monopolio del

3 Entendida la libertad como la libertad social, es decir, la relación del ciudadano con los demás, la libertad frente a los demás y, en las relaciones sociales, y civiles, para mejor comprensión del tema de la libertad, léase: VIVES ANTÓN Tomás y Otros (2000). Derecho Penal. Parte Especial. Valencia: Tirant to Blanch, 180 y ss. uso de la fuerza pública exclusivo del Estado, se efectúa a través de una política criminal la tipificación de una serie de bienes jurídicos que el legislador considera necesarios de protección, uno de ellos es por supuesto la seguridad pública. Así es que existen unos delitos que lesionan o ponen en peligro la seguridad de todos los ciudadanos, en general, todos ellos son tipos penales de peligro abstracto o presunto. Luego no es necesario que se utilice el objeto (bombas, armas, etc.), ni que se produzca el daño para que se tipifique el delito.

Por lo tanto, el terrorismo es tipificado como un hecho ilícito de acuerdo con el Artículo 343 de la Ley 599 de 2000, se asume que en principio, cualquier actividad desarrollada para apoyar o contribuir a acciones de terrorismo, entre ellas la financiación, que podría igualmente ser penalizada en Colombia a través de la tipificación del "concierto para delinquir".

De cualquier modo, el bien jurídico seguridad pública hace parte de los llamados de peligro abstracto, que según Muñoz Conde (2004, p. 240), «son aquellos delitos en los que el legislador describe una conducta, que, según la experiencia, suele ser peligrosa para un bien jurídico protegido, aunque en el caso concreto no lo sea». Tanto la seguridad pública como el DIH son delitos pluriofensivos «ya que la acción del autor ofende a la vez más de un bien jurídico» (Quintero O. G., 2000, p. 747).

Ahora vamos a elaborar un breve análisis de los tipos penales, teniendo en cuenta que pertenecen a dos bienes jurídicos distintos:

\section{Análisis del tipo penal acto de terrorismo}

\section{ARTÍCULO 144.ACTOS DE TERRORISMO}

El que, con ocasión y en desarrollo de conflicto armado, realice u ordene llevar a cabo ataques 
indiscriminados o excesivos o haga objeto a la población civil de ataques, represalias, actos o amenazas de violencia cuya finalidad principal sea aterrorizarla, incurrirá por esa sola conducta en prisión de doscientos cuarenta (240) a cuatrocientos cincuenta (450) meses, multa de dos mil seiscientos sesenta y seis punto sesenta y seis (2666.66) a cincuenta mil (50000) salarios mínimos legales mensuales vigentes, e inhabilitación para el ejercicio de derechos y funciones públicas de doscientos cuarenta (240) a trescientos sesenta (360) meses.

Respecto al sujeto activo que se enuncian en el tipo penal del artículo 144, es un sujeto activo indeterminado, en consecuencia puede ser cualquiera de las personas que dentro de un conflicto armado combaten a favor de cualquiera de las partes en contienda. Habría que acotar que los miembros de la Fuerza Pública en servicio activo pueden ser eventualmente imputados por los delitos en contra del DIH que se hallan en la ley penal ordinaria. Aunque, los hechos ilícitos cometidos por los miembros de la Fuerza Pública; son tanto aquellos que aparecen en el Código Penal Militar, como los que estén en el Código Penal común, los miembros de estas fuerzas serán procesados con fundamento en el Código de Procedimiento Penal y con fundamento de igual manera en el Código Penal si cometen hechos ilícitos que estén en contra del DIH (Código Penal Militar, Artículo 20). Bajo esa perspectiva, un militar en servicio activo será procesado si comete esta clase de delitos, y será competente para juzgarlo, la justicia penal ordinaria.

Los sujetos pasivos son todas las personas protegidas, de acuerdo con el artículo 135 del código penal se entiende por personas protegidas $^{4}$ aquellas que de conformidad con el derecho internacional humanitario se establecen así:
1. Los integrantes de la población civil.

2. Las personas que no participan en hostilidades y los civiles en poder de la parte adversa.

3. Los heridos, enfermos o náufragos puestos fuera de combate.

4. El personal sanitario o religioso.

5. Los periodistas en misión o corresponsales de guerra acreditados.

6. Los combatientes que hayan depuesto las armas por captura, rendición $u$ otra causa análoga.

7. Quienes antes del comienzo de las hostilidades fueren considerados como apátridas o refugiados. 8. Cualquier otra persona que tenga aquella condición en virtud de los Convenios I, II, III y IV de Ginebra de 1949 y los Protocolos Adicionales I y II de 1977 y otros que llegaren a ratificarse.

Como se ve, el primer lugar como sujeto pasivo - como no podía ser de otro modo- lo ocupa la población civil, considerada como tal aquella que no participa en las hostilidades. Según el protocolo I de los Convenios de Ginebra se define como población civil las personas que no pertenecen a ninguna de las categorías de combatientes 5 .

Hay que tener en cuenta la expresión conflicto armado como elemento normativo fundamental del tipo penal. El principal problema radica en que en el artículo 144, sé prohíbe tajantemente los actos terroristas en medio de los conflictos armados. Puesto que, la discusión se centra en si realmente existió o no un delito de terrorismo, para tal efecto la adecuación de determinadas

4 La definición tiene, naturalmente, su fundamento en las normas del Derecho de los Conflictos Armados (Derecho Internacional Humanitario y Derecho de la Guerra) integradas fundamentalmente por el artículo 13 común al I y II Convenios de Ginebra de 1949, artículo 4 común al III y IV Convenios de Ginebra de 1949, artículos 2.c y d, 8.a, b, c y d, 41.2, 44, 50 y 90 del Protocolo I de 1977, artículos 2, 4.1 y 3, y 5.1 y 3 del Protocolo II de 1977, así como el artículo 32 y concordantes del Reglamento Anexo al Convenio de La Haya de 1899.

5 Así en los artículos 48 a 51 del Protocolo I adicional de los Convenios de Ginebra, se prohíben los conflictos armados internos (como el colombiano) los ataques indiscriminados y los ataques o represalias contra: la población civil y las personas civiles. De la misma manera, la prohibición se extiende según los artículos 48 y 52 a los bienes de carácter civil; a los bienes indispensables para la supervivencia de la población civil en el artículo 54; a los bienes culturales y los lugares de culto en el artículo 53; a las obras y las instalaciones que contienen fuerzas peligrosas en el artículo 56 y finalmente en el artículo 55 prohíbe los ataques contra el medio ambiente natural. 
conductas humanas en un tipo penal de terrorismo, determina claramente la condición que habrá de darse al infractor de la ley, así por ejemplo, se debe determinar que existió el acto terrorista, esto es, que de manera efectiva la conducta humana investigada sea realmente un acto terrorista, con todas las características que este debe poseer, o si por el contrario, es un delito común. Ya que puede suceder que el acto de terrorismo no sea contra persona o bien protegida por el $\mathrm{DIH}$, sino que sea contra un objetivo militar, o no sé esté en medio del conflicto armado, en ese evento, el delito será de terrorismo tipificado en el artículo 343 del Código Penal.

Ahora bien, determinada esa indispensable condición, junto a la de la responsabilidad penal del sujeto activo, habrá de comprobarse lo más importante si esa conducta humana reprochable y punible se adecua al tipo penal en cuestión. Parece sencillo de interpretar ya que se determinará si la acción se realiza en medio de un conflicto armado internacional o no internacional. Por tanto, se debe establecer la condición de sí existe o no un conflicto armado, y en Colombia, a pesar de todo, como tal, (por el gobierno) no se reconoce que existe un conflicto armado no internacional.

Sin embargo, hay opiniones -que incluso van más allá-, Aponte (2006, p. 22) expresa qué: «un hecho fáctico incuestionable, que en Colombia hay guerra». Ante esa situación, se colige que tal vez, el adecuar una conducta humana en el tipo legal del artículo 144, sea sólo en los casos en que se violen principios consagrados en el

6 El Derecho de guerra al que me refiero es el D.I.H., no al derecho de guerra que por fuera de los parámetros jurídicos universales plantean los EE.UU. o el Reino Unido, para justificar sus acciones militares de corte terrorista en contra de Irak o Afganistán. Tampoco estoy de acuerdo con algunos de los capturados en acciones terroristas que exigen la condición de prisioneros de guerra. Esta es la misma teoría de Dershowitz, pero particularmente no estoy de acuerdo con su conclusión; cuando en defensa de la política invasora "antiterrorista" de los EE.UU., afirma: « no podemos quedarnos en la postur de tratar de acomodar nuestros actos de autodefense a formuciones anacrínicas que dan vertaja los de tratar de acomodar nuestros actos de autodefensa a formaciones anaconicas que dan ventaja a los hipócritame 2004). ¿Por que aumenta el terrorismo?. Madrid: Ediciones Encuentro, p. 250.

7 Tal como quedó plasmado en las sentencias de constitucionalidad C-574 de 1992 y C-225 de 1995. derecho de guerra ${ }^{6}$, que es lo que precisamente se busca proteger en el capítulo que corresponde a los delitos contra personas y bienes protegidos por el DIH del cual hace parte el mencionado artículo 144. Por consiguiente, a un individuo que cometa un crimen contra el DIH, le serían aplicables los Convenios de La Haya, los Convenios de Ginebra y los protocolos adicionales $^{7}$, además, eventualmente se podría castigar a un individuo si hay concurso con otro u otros de los delitos estipulados en ese capítulo, así por ejemplo, si hay perfidia para luego ejecutar un acto de terrorismo.

El designio principal del acto terrorista es aterrorizar; pero, puede haber otras finalidades de naturaleza secundaria, como es un delito precedente, concomitante o posterior al delito de acto de terrorismo. Por esta sola conducta sin necesidad de llevar a cabo otro hecho punible el delito se tipificaría. En cuanto a los verbos rectores, realizar, ordenar o llevar a cabo, el primero es ser ejecutor material del delito, ordenar es serlo pero en calidad de determinador del mismo y llevar a cabo es quien realiza el hecho punible.

Los ataques indiscriminados hacen referencia a que el objeto de ataque no es exacto, no está plenamente determinado. De igual modo, hay una especie de presunción de que el control referente a las armas $\mathrm{u}$ explosivos utilizados son plenamente conocidos y son manejados con propiedad por el terrorista, y en consecuencia estos criminales, saben discriminar a sus víctimas $\mathrm{y} / \mathrm{o}$ bienes y sobre todo saben del daño que potencialmente causaran. Lo excesivo es el exceso en el daño, cuando no se requería demasiado, casi siempre se asimila a la crueldad, de alguna manera van unidos. Reitero, la población civil es aquella parte de los pobladores que no participa en las hostilidades, por tanto la inmensa generalidad de la población. 


\section{El juzgamiento de delitos de Lesa Humanidad en el C.P. colombiano}

En los últimos años en el mundo se ha venido acrecentado el patrimonio de los Derechos Humanos, pero en países con constantes violaciones al DIH y con ofensas graves de Lesa Humanidad tal y como sucede en Colombia, aún sigue siendo un patrimonio que hay que defender. Es de matizarse que los Derechos Humanos tienen que cumplir con las llamadas "obligaciones erga omnes", lo que implica, que todos los Estados adquieren obligación de protegerlos. Uno de los objetivos perseguidos cuando se tipifican hechos punibles como los del artículo 144 es frenar, inhibir, disuadir al delincuente. Aunque, es sabido que en nuestro escenario es frecuente que las normas penales se queden en el simbolismo ${ }^{8}$, que se delinca además con excesos y con inusitado irraciocinio, en ocasiones con la venia del gobierno y con actores armados en los que es constante y reiterada la ejecución de delitos de Lesa Humanidad; todo ello no impide que se pretenda mejorar en cuanto a evitar impunidad.

Es pues indispensable que tales crímenes, independientemente del lugar en que se ejecuten y del tiempo que haya pasado, sus autores sean perseguidos y enjuiciados por esas conductas criminales. Fundamentados, para el efecto en la extraterritorialidad para juzgar delitos de lesa humanidad, se puede aplicar el principio de justicia universal que «permite asimismo y como en los casos anteriores ejercitar la jurisdicción del Estado más allá del lugar donde se extiende su soberanía y ello tanto si el delito ha sido cometido por nacionales como por extranjeros ${ }^{9} \gg$.

8 «Con esta expresión la doctrina se ha referido en los últimos años a aquel tipo de legislación producida de cara a la opinión pública para aparentar una efectividad de la tutela, pero en la conciencia de su real inefectividad». HASSEMER Winfred- MUÑOZ CONDE, Francisco (1989). Introducción a la Criminología y al Derecho penal. Valencia, p. 173.

9 LAMARCA PÉREZ Carmen (2001). El principio de justicia universal y la competencia de la jurisdicción española en los casos de Argentina y Chile, en el libro homenaje al Dr. Marino Barbero Santos, in memorian, Volumen II, dirigido por Luís A. Arroyo Zapatero e Ignacio Berdugo Gómez de la Torre, Salamanca: edit. Universidad de Castilla La Mancha, Universidad de Salamanca, p. 1100.
En consecuencia, la Comunidad Internacional (cualquier país lo podría hacer), puede asumir el compromiso de perseguir tales crímenes, o eventualmente aplicar el Estatuto de la CPI. En estas dos instancias de justicia, junto a la justicia ordinaria, se puede establecer la responsabilidad penal, del delincuente ejecutor de delitos de lesa humanidad. Cuestión posterior a la implacable persecución a que se somete a los delincuentes ya que el asilo político y el status de refugiados está a favor de la justicia y no del criminal; ese criminal luego, no podrá excusar su responsabilidad en virtud de obediencia debida; o la prescriptibilidad de sus crímenes. Mejor dicho, hoy se puede investigar y eventualmente castigar a todos los responsables de crímenes atentatorios del DIH, sin ningún tipo de distinción y en general de todos los casos de terrorismo. Inclusive los delitos de terrorismo de Estado que es de Lege Ferenda . Como también a los grupos que se han creado con su bendición y que han cometido delitos de Lesa Humanidad lo cual si es de lege data ${ }^{10}$.

En consecuencia, desde el prisma de la autoría se debe castigar a:

a) Quiénes dieron la orden, que serían según nuestro criterio los principales culpables, su responsabilidad sería agravada por que de ellos parte el preparar el plan (premeditación) son los que elaboran como se va a ejecutar y quienes lo van a realizar, es pues, responsable todo la cúpula de la organización criminal, inclusive si fuera el caso, los agentes del gobierno.

b) Quiénes cumplieron la orden, sin detenerse a

10 En otros términos no existe un tipo penal, ni en Colombia ni en el mundo que hable de la modalidad del llamado terrorismo de Estado. Entendiendo por tal aquel tipo de terrorismo que emana del Estado, por la importancia del mismo, traigo a colación la formulación propuesta sobre el terrorismo estatal, dad en mi tesis doctoral: El terrorismo de Estado se presenta al interior de un país y se puede valorar como un delito pluriofensivo, es el terror o la amenaza del mismo producido de forma explícita o implícita en un gobierno demócrata o autoritario de forma endémica, sistemática y generalizada. Sirve como medio adecuado para combatir cualquier intento de modificar la situación política, social o económica, de un adecuado para conbatir cus ocial o económica, de un país. Los actos de terror pueden, estar dirigidos contra un individuo o un grupo que mediante cualquier método pacifista ya sea beligerante o violento pretenda entorpecer al gobierno. Mediante el terror de Estado, se busca mejorar la gobernabilidad, mantener un control, obediencia y participación en la población. Como fin último en el terrorismo de Estado se quiere el mantenimiento del Statu quo mediante el uso del terror; dicho terror puede producirse mediante el uso del derecho o de la violencia política, en ambos casos con agresiones ilegítimas. En extenso sobre el tema: TORRES VÁSQUEZ Henry (2009). Terrorismo de Estado y Derecho penal. Bogotá D. C.: Grupo Editorial Ibáñez. 
analizar si era legítima o no, sin importar contra quién iba dirigida, responderán penalmente ya sea dolosa o culposamente ya que ejecutaron la orden sin denunciar tales crímenes.

c) Quiénes cumplieron una orden no contraria a derecho, pero la excedieron, estos sujetos serán responsables de acuerdo al tipo de orden que hayan recibido y evidentemente al tipo de "potestad" que tuvieron al momento de cometer el delito.

d) Para todos los copartícipes del hecho ilícito, hay que buscar la manera para evitar que por el transcurso del tiempo, o cualquier otro tipo de estratagema el sujeto activo del delito sea declarado inimputable.

En cuanto a la ausencia de responsabilidad penal que de acuerdo con el artículo 32-4 ${ }^{11} \mathrm{del}$ ordenamiento punitivo colombiano, sirve para la exoneración de responsabilidad opera ante una orden legítima de autoridad competente, la cual nunca podrá consistir en órdenes contrarias a los preceptos del Derecho Internacional Humanitario. Los cuales, como ha señalado la Corte Constitucional, hacen parte del bloque de constitucionalidad ${ }^{12}$.Hay que anotar que no se debe tener en cuenta el principio de la obediencia debida, ya que éste, es un resquicio de los famosos procesos militares, en los que existe impunidad ${ }^{13}$.

De no castigarse esa clase de delitos, se sigue ante una verdadera involución del derecho internacional, lo cual es el triunfo de la barbarie sobre la ley penal. Hay que recalcar un aspecto importante de lo dicho la obediencia debida no es una exención de responsabilidad en todos los casos. La Corte Constitucional ${ }^{14}$, declaró que si diera inmunidad total al subalterno militar lo convertiría en un peligro social. Del mismo modo dijo que: «las órdenes militares violatorias de los derechos fundamentales intangibles e inescindibles de la dignidad humana (Ley 137 de 1994, artículo $4^{\circ}$ ), no deben ser ejecutadas y que, en caso de serlo, tales órdenes no podrán ser alegadas como eximentes de responsabilidad».

\section{El concurso entre el delito de rebelión y el de terrorismo}

En el plano jurídico se trata de crear normas en las que se quite el contenido político a algunos delitos como la rebelión, sedición y asonada, para ello se crea un desprestigio social amplio sobre organizaciones consideradas de izquierda. De la misma manera, al menos hasta hace pocos años, y principalmente, en países Latinoamericanos se ha venido dando que algunos jueces consideren que existe concurso entre el delito de terrorismo y el de rebelión, su consideración se basa en que existe una conducta independiente cometida con dolo eventual como es el delito de rebelión y el cual no lleva implícito el propósito de producir terror y zozobra en la población, unida con un delito de terrorismo en el que sí hay dolo directo en vista del supuesto terror, temor o zozobra que ocasiona en la población los actos de terrorismo. Los actos de ferocidad, barbarie que son típicos

13 No obstante, se ha dicho que por razones políticas, como son los acuerdos de paz, son en alguno casos muy necesarios, ya que sirven para evitar retaliaciones y de ese modo llegar a que luego hay silencio y olvido. De esa manera se podría proteger a futuro tanto a personas como a bienes colectivos y se garantizaría la paz.

14 En esta oportunidad, la CORTE CONSTITUCIONAL en Sentencia No. C-578/95 de diciembre 4 de 1995, M.P. Dr. Eduardo Cifuentes Muñoz, dijo: Puede concluirse que la norma legal examinada es inconstitucional si se interpreta en sentido absoluto. La obediencia ciega, así como la correlativa irresponsabilidad absoluta del militar subalterno, repudian a la Constitución. De otro lado, la norma citad  Larca la exencion de rena. Las razos público, está vinculado al deber superior de respetar la ley y proteger efectivamente los derechos de la personas (C.P., arts. 2 y 6 ) 
del delito de terrorismo -tampoco son tipificados como en otrora se hiciera- como delitos de rebelión ${ }^{15}$. De otro lado, y es en la actualidad la corriente jurisprudencial mayoritaria, considera que no subsume la conducta punible de terrorismo en el delito de rebelión (Corte Suprema de Justicia Sala de Casación Penal, 2002b).En el delito de terrorismo hay dolo directo, ya que el agente de forma consciente y conociendo que es delito dirige su intención al resultado ${ }^{16}$, $\mathrm{y}$ seguramente hay concurso ideal o formal ${ }^{17}$, dado que, normalmente hay múltiples daños $y$, lo más preocupante, víctimas indefensas, así con una sola acción el sujeto activo comete varias acciones punibles. La naturaleza jurídica es la de los llamados delitos de peligro. En sentencia del Tribunal Nacional en 1996, en la que se estudiaba el caso de un individuo que pertenecía a un grupo guerrillero y que participó de un atentado terrorista, este individuo pretendía que su comportamiento delictivo y las múltiples secuelas del delito quedaran enmarcadas dentro del delito de rebelión. Según consideraba este señor, él enarbolaba las banderas del delito político, obviamente de esta manera, buscaba hacer menos grave su situación jurídica si triunfaba su petición, ya que no sería objeto de condena por otras conductas punibles.

\section{Lo ha reconocido varias veces la Sala de Casación} Penal de la Honorable Corte Suprema de Justicia, que es posible y jurídicamente advertible que el delito político concurse con otras modalidades de delincuencia, este concurso se da por que el delito político tiene una identidad propia y tiene como característica especial su fin altruista.

\footnotetext{
15 CORTE SUPREMA DE JUSTICIA, SALA DE CASACIÓN PENAL (2002a). Sentencia Nº 13307, M.P. Carlos Arturo Gálvez Argote, en esta sentencia la honorable Corte ha dicho: «no es admisible que a partir de la autoafirmación de pertenecer a un grupo rebelde cuyos actos se supone están orientados a derrocar el Gobierno Nacional mediante el empleo de las armas o a suprimir o modificar el régimen constitucional vigente, todos los actos con dicho cometido realizados puedan quedar comprendidos dentro de la calificación de constituir una manifestación más del combate, en el ilimitado sentido que el casacionista promueve. De hecho en el propio texto de la norma cuya violación se acusa, se exceptuaban de la exclusión punitiva, aquellos actos de ferocidad, barbarie o típicos de terrorismo».

16 De acuerdo al artículo 22 del código penal, La conducta es dolosa cuando el agente conoce los hechos constitutivos de la infracción penal y quiere se realización.

17 El cual se da cuando un mismo comportamiento humano se subsume simultáneamente en dos o más tipos penales que no se excluyen entre sí.
}

Lo que sucede es que cuando se lesionan o se ponen en peligro otros bienes jurídicos tutelados por el legislador y estos sobrepasan los fines altruistas a más de tener identidad propia, son delitos que no se pueden subsumir en el delito político. «Es bien sabido que el punible de rebelión y de terrorismo, andan por senderos idénticos en procura de desestabilizar el Estado, por cuanto en desarrollo de sus actividades, tales organizaciones criminales han ejecutado diversas conductas punibles, muchas de ellas con el fin exclusivo de causar la natural zozobra en la ciudadanía y mostrar ante la Nación el poder que les acompaña y la impotencia del Estado para reprimir sus acciones.

Por el amplio espectro de su cobertura que afecta por igual porciones importantes de la población y de los bienes y por la influencia devastadora sobre el resto de la Nación, es que se ha tildado estos comportamientos de terroristas» (Tribunal Nacional, 1996).

La especificidad del delito de rebelión ${ }^{18}$ como delito político por excelencia, exige que debe ser una violencia normal, aun con el empleo de armas no puede haber una violencia extrema. $\mathrm{Su}$ fin es de hecho el pretender derrocar el gobierno nacional, o suprimir o modificar el régimen constitucional o legal vigente. Al hablar del delito de rebelión, se requiere estar en las precisas condiciones impuestas en el código penal y en la interpretación jurisprudencial, de lo contrario se pasa con suma facilidad a un delito de terrorismo.

De tal modo que para tipificarse un delito de rebelión, la conducta humana, la exteriorización del inconformismo de los grupos guerrilleros se puede hacer siempre que: «se hicieran 18 Artículo 467. Rebelión. Penas aumentadas por el artículo 14 de la Ley 890 de 2004, a partir del 1 o.
de enero de 2005. El texto con las penas aumentadas es el siguiente: Los que mediante el empleo de
las armas pretendan derrocar al Gobierno Nacional, o suprimir o modificar el régimen constitucional o
legal vigente, incurrirán en prisión de noventa y seis (96) a ciento sesenta y dos (162) meses y multa de
ciento treinta y tres punto treinta y tres (133.33) a trescientos (300) salarios mínimos legales mensuales vigentes. 
manifestaciones de inconformidad dentro de unos parámetros entendibles y se actuara dentro de criterios que menoscabaran la seguridad y la tranquilidad de la población civil; porque, es del talante del delito político el ataque al régimen constitucional. Pero bien distinto es aquel que menoscaba la Seguridad Pública, desbordando el ataque a las instituciones mismas e ingresando al campo del ataque de los derechos propios de los ciudadanos» (Tribunal Nacional, 1996).

En jurisprudencia del año 1994, parece entenderse que la cantidad de explosivos tiene una gran incidencia en la determinación del delito de terrorismo, si la cantidad utilizada tiene suficiente poder destructivo esta acción ilícita se incluye en los delitos de terrorismo, al contrario, si la cantidad es menor, es posible que ésta conducta sea subsumida en el delito de rebelión. Esto debido a que el terror causado a la población es proporcional a la cantidad de explosivos utilizados y a la magnitud de la explosión de los mismos. «El acto terrorista puede ser realizado con dolo indirecto o eventual y éste se deduce del medio utilizado, del lugar en que se ejecuta el hecho y de la indiferencia del autor no obstante, que es claro, ostensible y evidente que con esa conducta se generará una situación de terror, zozobra y alarma colectiva» (Corte Suprema de Justicia Sala de Casación Penal, 1994).

Hay que indicar igualmente que, se tipifica tal acción como terrorismo, no sólo por la cantidad de explosivos, si no también, si el ataque se da en condiciones de extrema violencia y sin miramientos de las consecuencias de su accionar. Del mismo modo hay que decir que se tipifica como terrorismo si el accionar de guerra, es un acto propio de combate, con factor sorpresa y dentro de la guerra de guerrillas, dicho de otro modo, dentro de los parámetros de una rebelión mesurada en sus actos violentos. De otra parte, es oportuno manifestar que en Colombia, entre
1987 y 1993 hubo intensos actos terroristas que fueron llevados a cabo por «narcotraficantes y sus truculentos aliados» (Pecaut D., 2001).

Ese tipo de terrorismo es todavía más letal para las personas y bienes protegidos, ya que estos terroristas tienen un gran poder económico. «La violencia narcoterrorista coloca en situación de indefensión a la sociedad civil, bajo la amenaza de padecer, males irreparables, si se opone a sus proditorios designios. La acción delictiva de la criminalidad común no se dirige contra el Estado como tal, ni contra el sistema político vigente buscando sustituirlo por otro distinto, ni persigue finalidades altruistas, sino que se dirige contra los asociados que se constituyen así en víctimas indiscriminadas de esa violencia (...), los hechos atroces que en que incurre el narcoterrorismo (...) constituyen delito de Lesa Humanidad que jamás podrán encubrirse con el ropaje de delitos políticos» (Corte Constitucional, 1996). La consideración de narcoterrorismo surgió en el gobierno Reagan, según Glover (Collins J. Y Glover R., 2003) describía a las personas contra las que supuestamente estaban combatiendo en Centroamérica, cuando en realidad, los EE.UU. comercializaban tanto narcóticos como armamento ilegales.

Finalmente, los delitos que están en el código penal y que son contra personas y bienes protegidos por el Derecho Internacional Humanitario, tienen que denunciarse por los particulares de lo contrario se incurre en un delito; además, cuando quien omita denunciar sea un servidor público la pena se agrava ${ }^{19}$.

Para entender el tema del terrorismo en condiciones normales, es decir el terrorismo que

19 ARTíCULO 9o. El artículo 441 de la Ley 599 de 2000, tendrá un inciso 2o. Omisión de denuncia de particular. El que teniendo conocimiento de la comisión de delitos de genocidio, desplazamiento forzado, tortura, desaparición forzada, homicidio, secuestro, secuestro extorsivo o extorsión, narcotráfico, tráfico de drogas tóxicas, estupefacientes o sustancias sicotrópicas, enriquecimiento ilícito, testaferrato, lavado de activos, cualquiera de las conductas contra personas y bienes protegidos por el Derecho Internacional Humanitario o de las conductas de proxenetismo cuando el sujeto pasivo sea un menor de doce (12) años, omitiere sin justa causa informar de ello en forma inmediata a la autoridad incurrirá en prisión de dos (2) a cinco (5) años. La pena se aumentará en la mitad para el servidor público que cometa cualquiera de las anteriores conductas de omisión de denuncia. 
no se da en medio del conflicto armado. Se tiene que estudiar el terrorismo que se haya definido en el artículo 343 de nuestro ordenamiento penal. Junto al lado de los delitos más comunes en la criminalidad organizada, ameritan el reproche punitivo en forma de severas penas y de esa manera tratar de reprimir y prevenir conductas alusivas al terrorismo.

\section{Análisis del artículo 343 del Código Penal colombiano}

Artículo 343. TERRORISMO: El que provoque o mantenga en estado de zozobra o terror a la población o a un sector de ella, mediante actos que pongan en peligro la vida, la integridad física o la libertad de las personas o las edificaciones o medios de comunicación, transporte, procesamiento o conducción de fluidos $\mathrm{o}$ fuerzas motrices, valiéndose de medios capaces de causar estragos, incurrirá en prisión de ciento sesenta (160) a doscientos setenta (270) meses y multa de mil trescientos treinta y tres punto treinta y tres (1.333.33) a quince mil (15.000) salarios mínimos legales mensuales vigentes, sin perjuicio de la pena que le corresponda por los demás delitos que se ocasionen con esta conducta. Si el estado de zozobra o terror es provocado mediante llamada telefónica, cinta magnetofónica, video, casete o escrito anónimo, la pena será de treinta y dos (32) a noventa (90) meses y la multa de ciento treinta y tres punto treinta y tres (133.33) a setecientos cincuenta (750) salarios mínimos legales mensuales vigentes.

Aquí hay lugar a recordar que, el terrorismo estipulado en este artículo, es un acto violento o la advertencia de apelar a él dirigido contra la colectividad, tiene como propiedad que en sus efectos no se hace ningún tipo de diferencia. Siendo además impreciso en cuanto al objeto de ataque, por tanto los daños colaterales son indescifrables. Del mismo modo, he de decir que, el delito de terrorismo es un tipo penal abierto, de tal manera, que se pueden inscribir en él todos aquellos comportamientos delictivos que causan terror, zozobra, o pánico en la sociedad o en parte de ella.

En el artículo 343 del Código Penal colombiano, se señala como sujeto activo al que provoque o mantenga en estado de zozobra o terror a la población o a un sector de ella, hay que añadir que cualquier persona puede ser sujeto activo del hecho punible. Así mismo, puede ser ejecutado el acto terrorista a título individual o en grupo, en este caso es probable que, se castigue además como, concierto para delinquir (Código Penal, Artículo 340) $)^{20}$.

Hay que hacer advertencia a la clase de actos que son necesarios para tipificarse el delito de terrorismo, estos son los que pongan en peligro la vida, la integridad física o la libertad de las personas o las edificaciones o medios de comunicación, transporte, procesamiento o conducción de fluidos o fuerzas motrices.

En este tipo penal se enuncia la calidad que deben tener los medios utilizados para determinar que el delito es de terrorismo, de ahí que, cuando se dice la clase de ataque y la entidad de los medios utilizados estos deben ser: Medios capaces de causar estragos, y tiene una rebaja sustancial de la pena cuando el estado de zozobra o terror es provocado mediante llamada telefónica, cinta magnetofónica, vídeo, casete o escrito anónimo. En cuanto al sujeto pasivo puede ser cualquier persona.

La Corte Suprema de Justicia ha dicho: «es posible que con un acto terrorista se persiga atacar a una determinada persona, familia o entidad, sin que por eso el hecho pierda especial connotación; o dicho de otra manera, una

20 Reformado por el artículo 8 de la ley 733 de 2002. 
acción realizada con un fin particular puede llevar implícito el carácter terrorista». «El acto terrorista puede ser realizado con dolo indirecto o eventual, y éste se deduce del medio utilizado, del lugar en que se ejecuta el hecho, y de la indiferencia del autor no obstante, que es claro, ostensible y evidente, que con esa conducta se generará una situación de terror, zozobra y alarma colectivas $\left.{ }^{21}\right\rangle$.

Por su parte la Corte Constitucional considera que: «el "terrorismo" es un delito dinámico y se diferencia por tanto de los demás tipos. Como conducta responde a unas características diferentes de cualquier tipo penal, por lo siguiente: Primero, es pluriofensivo pues afecta o puede llegar a afectar varios bienes jurídicos protegidos por el ordenamiento penal. Segundo, obedece a organizaciones delincuenciales sofisticadas. Tercero, el terrorista demuestra con su actitud una insensibilidad frente a los valores superiores de la Constitución Política, que son un mínimo ético, al atentar indiscriminadamente contra la vida y dignidad de las personas») (Corte Constitucional, 1993).

La ausencia del elemento subjetivo hace atípica la conducta terrorista, aún cuando lo parezca. Así por ejemplo cuando hay un asesinato de una persona muy importante (magnicidio), se diría se cumplen los elementos normativos del tipo penal, no así el elemento subjetivo del tipo. Por lo tanto, no se cumple con el objetivo del terrorismo, con el elemento esencial para que un hecho punible violento sea tipificado como un delito de terrorismo, esto es: provocar o mantener en estado de zozobra o terror a la población o a un sector de ella.

\section{Las circunstancias de agravación del delito de terrorismo}

Artículo 344. CIRCUNSTANCIAS DE AGRAVACION PUNITIVA. Las penas

21 CORTE SUPREMA DE JUSTICIA, SALA DE CASACIÓN PENAL, diciembre 14 de 1994, M.P. Ricardo Calvete Rangel. Radicado № 9897. señaladas en el inciso primero del artículo anterior, serán de ciento noventa y dos (192) a trescientos sesenta (360) meses de prisión y multa de seis mil seiscientos sesenta y seis punto sesenta y seis $(6.6666 .66)$ a cuarenta y cinco mil (45.000) salarios mínimos legales mensuales vigentes, cuando: 1 . Se hiciere copartícipe en la comisión del delito a menor de dieciocho (18) años; 2. Se asalten o se tomen instalaciones de la Fuerza Pública, de los cuerpos de seguridad del Estado, o sedes diplomáticas o consulares; 3. La conducta se ejecute para impedir o alterar el normal desarrollo de certámenes democráticos; 4. El autor o partícipe sea miembro de la Fuerza Pública o de organismo de seguridad del Estado; 5. Cuando la conducta recaiga sobre persona internacionalmente protegida diferente de las señaladas en el título II de este Libro, o agentes diplomáticos de conformidad con los Tratados y Convenios Internacionales ratificados por Colombia, o se afecten edificaciones de países amigos o se perturben las relaciones internacionales.

Al analizar este artículo hay que acotar que las agravantes son de naturaleza represiva universalmente reconocida, así, es necesario puntualizar los siguientes aspectos:

1. El menor de dieciocho años (18), puede participar en cualquiera de las formas de coparticipación delictiva establecida en los artículos 29 y 30 del C.P., es importante advertir que en caso de ser el menor copartícipe por su propia voluntad, estará sujeto a la normativa que sobre menores exista, si el menor ha sido obligado, lo que casi siempre sucede, la conducta deviene en causal de inimputabilidad.

2. La manera de proteger la posibilidad de enfrentar un posible lío diplomático, se hace a través de la causal de agravación, esto en razón de la protección máxima que debe darse a algunas sedes diplomáticas o consulares que han sido catalogadas como objetivo militar por algunos grupos terroristas. 
3. En el artículo se alude a cualquier tipo de certamen electoral, inclusive desde la misma campaña política y se pretende proteger todos aquellos mecanismos de participación ciudadana, como pueden ser plebiscitos, referéndum, etc.

4. La Fuerza Pública comprende tanto a los militares como a los policías, y los organismos de seguridad como el Departamento Administrativo de Seguridad (DAS), por ejemplo.

5. Ya se hacía alusión a los delitos que comprende el título II del Código Penal, aquellos delitos que están estipulados bajo el epígrafe delitos contra las personas protegidas por el $\mathrm{DIH}$, en cuanto a las instalaciones o edificaciones de países amigos, luego, hay que afirmar que, igual sucede por extensión para los que no sean amigos toda vez que si el temor es que no se perturben las relaciones internacionales, imagínense si se atacan agentes diplomáticos o edificaciones de países enemigos de Colombia.

Recuérdese que el bien jurídico penalmente protegido es, la seguridad pública y esta a raíz de las circunstancias de violencia generalizada ha visto como plausible el aumento de penas en los delitos de terrorismo, pero hay que matizar, que el aumento de penas resulta menos eficaz que para otra clase de delitos. Los delincuentes terroristas no responden al modelo de racionalidad común. Es pues ineficaz el derecho penal en estos casos como mecanismo de intimidación. Entonces amenazar con severas penas no es lo más conveniente con terroristas, «Ello se debe a que el delincuente terrorista no tiene en cuenta la amenaza de pena en su ponderación previa a la comisión del delito» (Silva Sánchez J. M. y Otros, 2005, pp. 121122). Esta apreciación es tan válida que en salvamento de voto de la Corte Constitucional (1993) se dijo: «el expediente ineficaz y manido de las penas duplicadas constituyen una amenaza mayor para los inocentes que para los criminales de oficio».

\section{CONCLUSIONES}

Respecto a los bienes jurídicos protegidos en el código penal colombiano son exactamente dos: de un lado el Derecho Internacional Humanitario y de otro lado la Seguridad Pública. No obstante, existen desavenencias respecto a la falta de una concreción del término terror, terrorismo o terrorista, de los cuales hay que decir, no existe en la doctrina y en la jurisprudencia nacional e internacional la unanimidad necesaria para evitar la laxitud de los tipos penales en los que se tipifica el terrorismo.

A pesar de que el terrorismo nunca ha tenido éxito, la estrategia del terror y la táctica de hacer la guerra contra la población civil con actos de terrorismo, es usada frecuentemente por los distintos actores de la violencia. Está apreciación adquiere un mayor realce cuando hablamos de la degradación del conflicto o de la llamada "guerra sucia," que tanto éxito ha tenido en distintas partes (Waldmann P. y Reinares F., 1999, p. 248). Sin olvidar que existen regímenes totalitarios que para asegurarse el poder "crean" un enemigo el terrorismo, y se escudan en la libertad como valor supremo o como dice Imposimato (Souaidia H. 2002, p. 33) «luchan en nombre de la libertad y de la «democracia» y se amparan en los derechos del hombre», todo ello es absolutamente contradictorio, ya que con terrorismo, permitiendo o aliándose con el mismo no se logra ni libertad y al contrario se destruye la democracia. En cualquier caso hay razones suficientes para proscribir el terrorismo, pero siendo realistas, los Estados están lejos de lograrlo, quizá por no atender a las causas del terrorismo o bien por qué siguiendo a Carr (2002, p. 152) «debemos remontarnos a la historia de la guerra, y no al extremismo político, si queremos determinar la mejor manera de responder a la amenaza terrorista». 
Es fundamental entender que es necesario consensuar el concepto de terror, terrorismo y de terrorista en aras de garantizar el principio de legalidad, para no encuadrar conductas humanas que en absoluto tienen que ver con el aspecto teleológico que por política criminal se quiere tutelar.

En ese aspecto, es de estar de acuerdo con Márquez (Márquez Cárdenas A. y Paz G. 2008, p. 30) cuando propone que se diferencie entre concierto para delinquir y coautoría de tal manera que no se viole el principio nom bis in ídem ya que, en algunos casos, sucede lo contrario, se sancionan dos veces los actos preparatorios. 


\section{BIBLIOGRAFÍA}

APONTE CARDONA (2006). Guerra y derecho penal del enemigo. Bogotá D. C.: Grupo Editorial Ibáñez.

(2006). Derecho penal de enemigo o derecho penal del ciudadano. Bogotá D. C.: Ed. Temis.

CARR, C. (2002). Las lecciones del terror. Orígenes históricos del terrorismo internacional. Barcelona: Ediciones B. S.A.

CÓDIGO PENAL.

CÓDIGO PENAL MILITAR, Artículo 20.

COLLINS J. y GLOVER R. (2003). Lenguaje Colateral, Claves para justificar una guerra. Madrid: Ed. Páginas de Espuma.

CORTE CONSTITUCIONAL COLOMBIANA (1993). Sentencia C-127, M. P. Alejandro Martínez Caballero.

CORTE CONSTITUCIONAL (1994). Sentencia C-574, revisión oficiosa del Protocolo I Adicional a los Cuatro Convenios de 1949.

CORTE CONSTITUCIONAL (1996). Sentencia No 709, M. P. Dr. Antonio Barrera Carbonell.

CORTE CONSTITUCIONAL (1995). Sentencia No. C-578, M. P. Dr. Eduardo Cifuentes Muñoz.

CORTE SUPREMA DE JUSTICIA, SALA DE CASACIÓN PENAL (1989). Auto del 6 de septiembre, M. P. Jorge Carreño Luengas.

CORTE SUPREMA DE JUSTICIA, SALA DE CASACIÓN PENAL (1994). Auto de diciembre 14 de 1994. M. P. Dr. Ricardo Calvete Rangel.

CORTE SUPREMA DE JUSTICIA, SALA DE CASACIÓN PENAL (2002a). Sentencia Nº 13307, M. P. Carlos Arturo Gálvez Argote.

CORTE SUPREMA DE JUSTICIA, SALA DE CASACIÓN PENAL (2002b). Radicado No 13053, M. P. Jorge Aníbal Gómez Gallego.

DERSHOWITZ A. M. (2004). ¿Por qué aumenta el terrorismo?. Madrid: Editorial Encuentro.

GARCÍA ARÁN, M. y LÓPEZ GARRIDO, D. (2000). Crimen internacional y jurisdicción universal. Valencia: Tirant to Blanch. 
HASSEMER W. y MUÑOZ C. F. (1989). Introducción a la Criminología y al Derecho penal. Valencia.

SOUAIDIA, H. (2002). La guerra sucia. Barcelona: Ediciones B. S.A.

LAMARCA P. C. (2001). El principio de justicia universal y la competencia de la jurisdicción española en los casos de Argentina y Chile. En el libro homenaje al Dr. Marino Barbero Santos, Volumen II, dirigido por Luis A. Arroyo Zapatero e Ignacio Berdugo Gómez de la Torre. Salamnca: Ed. Universidad de Castilla La Mancha, Universidad de Salamanca.

MÁRQUEZ CÁRDENAS, A. y PAZ G. (2008). Diferenciaciones dogmáticas del delito de concierto para delinquir frente a la coautoría. Revista Diálogos de saberes, No 29 julio-diciembre. Bogotá: Universidad Libre.

PECAUT, D. De la banalidad de la violencia al terror real: El caso de Colombia. En: KEES, K. y DIRK K. (eds.) (2001). Las sociedades del miedo. El legado de la guerra civil, la violencia, y el terror en América Latina, [traducción Jesús Torres del Rey y otros]. Salamanca: Ediciones Universidad de Salamanca.

SILVA SÁNCHEZ, J. M. y Otros (2005). La seguridad en la sociedad del riesgo. Un debate abierto. Universitat Pompeu Fabra.

TORRES VÁSQUEZ H. (2009) Terrorismo de Estado y Derecho penal. Bogotá: Ed. Grupo Editorial Ibáñez.

TRIBUNAL NACIONAL (1996). Sala de Decisión, Radicación No 9282.

VIVES A. T. y Otros (2000). Derecho Penal. Parte Especial. Valencia: Ed. Tirant lo Blanch.

WALDMANN, P. y REINARES F. (comp.) (1999). Sociedades en guerra civil. Conflictos violentos de Europa y América Latina. Madrid: Ed. Paidós. 